\title{
Tolerância à germinação na espiga em cultivares de trigo colhido na maturação fisiológica
}

\author{
Sprouting tolerance on spikes in wheat cultivars harvested in the physiological ripening
}

\author{
Francisco de Assis Franco $^{I^{*}}$ Ronald José Barth Pinto $^{\mathrm{II}}$ Carlos Alberto Scapim ${ }^{\mathrm{II}}$ Ivan Schuster $^{\mathrm{I}}$ \\ Crisleine Thomann Predebon ${ }^{\mathrm{I}}$ Volmir Sergio Marchioro ${ }^{\mathrm{I}}$
}

\section{RESUMO}

O objetivo deste trabalho foi identificar as diferenças de tolerância à germinação na pré-colheita em espigas de cultivares de trigo, submetidas a um sistema de chuva artificial. Foram realizados experimentos em duas localidades do Paraná (Palotina e Cascavel) com 12 cultivares. Quando as cultivares atingiram a maturidade fisiológica, as espigas foram colhidas e secadas em temperatura ambiente por um período de 20 dias. Foram analisadas 10 espigas por cultivar e submetidas a um sistema de chuva artificial. Após o período de molhamento, foram realizadas leituras pela escala de notas de 1 a 11 . As espigas foram então debulhadas $e$ submetidas à contagem de grãos germinados e não germinados. Esses resultados possibilitaram identificar as cultivares 'Frontana', 'IAPAR 53', 'ONIX', 'CD 108'e 'IPR 85' como as de maior nível de tolerância. Considerando todas as características avaliadas, 'Frontana' foi a cultivar com maior potencial de utilização no melhoramento genético. O emprego de notas visuais de germinação na espiga foi vantajoso porque permitiu a realização de avaliações rápidas e precisas em um grande número de cultivares, sem comprometer os resultados de seleção dos genótipos tolerantes.

Palavras-chave: Triticum aestivum (L.), germinação na précolheita, dormência.

\section{ABSTRACT}

The objective of the study was to identify the differences in pre-harvest sprouting tolerance in wheat spikes cultivars analyzed in artificial rain. Experiments were carried out in two locations of Paraná, Brazil (Palotina and Cascavel) with 12 cultivars. Spikes from plants in physiological maturation were harvested and dried at room temperature for 20 days. Ten spikes per cultivar were used and subjected to artificial rain. After the wetness duration were recorded notes from scale 1 to 11. In the next step, spikes were threshed and subjected to counting of sprouted and nonsprouted seeds. This results made possible to identify 'Frontana', 'IAPAR 53', 'ONIX', 'CD 108' and 'IPR 85' as the cultivars with the best level of tolerance. In general, Frontana was the most promising cultivar to be used in breeding programs. The use of visual grades as criteria of sprouting in the ears permitted a prompt and accurate evaluation of great number of cultivars without affecting the results of tolerant genotypes selection.

Key words: Triticum aestivum (L.), pre-harvest sprouting, dormancy.

\section{INTRODUÇÃO}

Muitas regiões produtoras de trigo apresentam incidência de germinação na pré-colheita. O problema ocorre em vários continentes, com destaque para o norte e o oeste da Europa, noroeste dos Estados Unidos, norte da Austrália, oeste da Nova Zelândia, Canadá, África do Sul, Chile, Argentina e Brasil (CUNHA et al., 2004). Assim, na Austrália, ocorrem grandes perdas por germinação na pré-colheita (FLINTHAM, 2000). Da mesma forma, no Reino Unido, a germinação na pré-colheita é a principal fonte de danos nas culturas comerciais (LUNN et al., 2001). Analogamente, no Brasil, a ocorrência de chuvas antes e durante da colheita provoca grandes perdas por germinação (BASSOI, 2004).

A temperatura é um dos fatores que contribui para a expressão da germinação na pré-colheita. Os efeitos da temperatura, no período entre o enchimento

ICooperativa Central de Pesquisa Agrícola (Coodetec), BR 467, Km 98, CP 301, 85813-450, Cascavel, PR, Brasil. E-mail: franco@coodetec.com.br. *Autor para correspondência.

"Departamento de Agronomia, Universidade Estadual de Maringá (UEM), Maringá, PR, Brasil. 
de grãos e a colheita, interferem na determinação do grau de dormência (HILHORST, 1995). Após a maturação, ocorre uma correlação positiva entre a baixa dormência e a alta temperatura (BELDEROCK, 1976; HILHORST, 1995), mas a temperatura baixa pode contribuir para aumentar a dormência durante o período de enchimento de grãos e reduzir a dormência na maturação (REDDY et al., 1985). A expressão da dormência nos cereais ocorre quando as sementes, morfologicamente maduras e sadias, não germinam quando colocadas sob condições adequadas de umidade, temperatura, luz e oxigênio (CASTRO et al., 2004). Por outro lado, a ausência de dormência pode resultar na germinação prematura das sementes, quando expostas à alta umidade próxima ao ponto de maturidade fisiológica (HILHORST, 1995).

As metodologias desenvolvidas para a determinação de germinação na espiga podem requerer o uso de câmaras de germinação com alta umidade relativa e o emprego de simuladores de chuva (McMASTER \& DERERA, 1976; REIS \& CARVALHO, 1989; OKUYAMA et al., 2003; BASSOI \& FLINTHAM, 2005; BASSOI et al., 2006). O uso de uma escala de notas também pode ser útil na avaliação do grau de germinação das espigas (McMASTER \& DERERA, 1976; REIS \& CARVALHO, 1989; OKUYAMA et al., 2003), bem como na determinação do número de grãos germinados e não germinados (BASSOI et al., 2006).

Um novo gene que determina a dormência na pré-colheita, associado à expressão da cor vermelha no grão, foi detectado por FLINTHAM (2000). KATO et al. (2001) identificaram um QTL principal, localizado no braço longo do cromossomo 4AL, que pode explicar mais de $77 \%$ do efeito para dormência. No entanto, a obtenção da tolerância à germinação depende de uma interação entre os fatores ambientais e os genes envolvidos na herança de diferentes caracteres (BASSOI et al., 2006). Para caracterizar essas diferenças de tolerância à germinação em espigas na pré-colheita, BASSOI \& FLINTHAM (2005) utilizaram um simulador de chuva durante três anos. Os autores constataram que os genes responsáveis pela determinação de cor de grão tiveram forte efeito na expressão da tolerância e que havia mais outros genes envolvidos com tolerância à germinação na pré-colheita.

Neste trabalho, as avaliações objetivaram detectar as diferenças de tolerância à germinação na espiga. A identificação de cultivares de trigo portadoras de dormência poderá permitir, no futuro, a transferência desse atributo às cultivares de grande potencial agronômico, representando uma estratégia para minimizar o problema, especialmente nas regiões onde a germinação na espiga vem sendo observada com maior freqüência.

\section{MATERIAL E MÉTODOS}

Foram avaliadas a campo 12 cultivares de trigo: ‘BRS 177’; 1BRS 208'; 'BRS 210’; ‘CD 104’; ‘CD 105’; 'CD 108'; ‘Frontana'; 'IAPAR 53’; 'IPR 85’; 'OCEPAR 18', 'ÔNIX'; 'Trigo BRS 18-Terena'. Os experimentos foram instalados em blocos casualizados completos, com quatro repetições, em 22 de abril e em 14 de maio de 2005, nos Centros de Pesquisa da Coodetec, em Palotina e Cascavel, no Paraná. As doenças foram controladas conforme recomendações técnicas para a cultura do trigo (IAPAR, 2003), no período de desenvolvimento da cultura, até a fase final do enchimento de grãos. A colheita foi realizada no estádio de maturidade fisiológica. Seguindo indicação de HANFT \& WYCH (1982), foram consideradas plantas fisiologicamente maduras quando as espigas perderam a coloração verde, mas os nós dos colmos ainda se mantinham verdes. Cinquenta espigas de cada repetição foram colhidas e posteriormente secadas em temperatura ambiente, sob um telado coberto, durante 20 dias, até atingirem aproximadamente 13\% de água.

A condição propícia para simular a precipitação na pré-colheita, provocando a germinação na espiga, foi obtida pelo emprego de um simulador de chuva em uma casa de vegetação. O modelo corresponde a uma versão do simulador usado por OKUYAMA et al. (2003), com suporte no modelo obtido por McMASTER \& DERERA (1976) e HAGEMANN \& CIHA (1984). Para distribuir as espigas em mesas, foram colocados isopores de poliestireno de $6 \mathrm{~cm}$ de espessura, com perfurações equidistantes $5 \mathrm{~cm}$ umas das outras, na horizontal e na vertical. Durante o corte das espigas, os pedúnculos foram cortados a $4 \mathrm{~cm}$ da base. Como as espigas foram inseridas a $2 \mathrm{~cm}$ de profundidade, no isopor, a folga de $2 \mathrm{~cm}$ evitou o contato direto das mesmas com a umidade do isopor. $\mathrm{O}$ sistema de chuva artificial permaneceu ligado por uma hora, com interrupção de 15 minutos, durante dois dias e meio. A quantidade total de chuva programada alcançou 993mm. A temperatura e a umidade relativa foram registradas durante todo o período.

Para a caracterização dos genótipos quanto à germinação na espiga, foram preparadas 10 espigas por repetição e por tratamento. Após a finalização do período de molhamento, foram realizadas leituras pela escala de notas de 1 a 11 proposta por McMASTER \& DERERA (1976). As notas de cada material foram tomadas, separadamente, de duas formas: a primeira (notas visuais de germinação na espiga), mediante uma rápida inspeção visual das espigas, simulando as condições expeditas da avaliação que constituem o trabalho cotidiano do melhorista, e a segunda (notas 
de germinação), através da contagem e mensuração de radículas e de folhas presentes em cada espiga.

Após a atribuição das notas, as espigas foram secadas e debulhadas manualmente, sendo então submetidas à contagem de grãos germinados e não germinados. Em razão da variação do tamanho das espigas, esses resultados foram convertidos em percentagem. Os grãos que não germinaram foram submetidos ao teste de tetrazólio para confirmar a existência de dormência, em quatro amostras de 50 sementes (BRASIL, 1976).

Os resultados obtidos quanto ao número de grãos, número de grãos germinados, grãos não germinados e notas de germinação foram submetidos ao teste de normalidade e homogeneidade de variâncias, utilizando-se o software GENES (CRUZ, 2001). Em seguida, foi realizada a análise conjunta dos experimentos individuais nas duas localidades. As comparações entre as médias foram realizadas pelo teste de Scott \& Knott a 5\% de probabilidade de erro. As médias das características analisadas foram submetidas à análise de correlação de Pearson.

\section{RESULTADOS E DISCUSSÃO}

A tabela 1 apresenta as médias de número de grãos, número de grãos germinados e número de grãos não germinados dos experimentos de Cascavel e Palotina. Embora as diferenças entre cultivares, em Cascavel, quanto ao número de grãos por espiga, não tenham sido significativas, foi observada em Palotina a superioridade das cultivares 'CD 104', 'BRS 208' e 'Frontana'.
O número de grãos por espiga é um componente fortemente associado ao rendimento de grãos (FRANCO \& CARVALHO, 1985) e decorre do número de grãos por espigueta e do número de espiguetas por espiga. É provável que a base genética do trigo nacional, proveniente da 'Frontana', tenha transmitido esse componente para a descendência, o qual pode ter contribuído no acréscimo de rendimento de grãos das novas cultivares. As cultivares 'CD 104' e 'BRS 208' foram obtidas a partir do desenvolvimento de materiais procedentes do programa de melhoramento do CIMMYT. Elas ocupam hoje uma área que perfaz aproximadamente 50\% da área de cultivo do Paraná, sendo as duas cultivares mais utilizadas no Estado.

A simulação de chuva em ambiente controlado foi eficiente para promover a germinação na espiga em cultivares suscetíveis. Neste caso, o menor número de grãos germinados e o maior número de grãos não germinados possibilitaram qualificar como tolerantes as cultivares 'Frontana', 'IAPAR 53', 'ÔNIX', 'CD 108' ' 'IPR 85' (Tabela 1). Os resultados permitem supor que, em Cascavel, as condições ambientais foram menos favoráveis para expressar a tolerância. No caso, as três primeiras cultivares tiveram destaque pela menor possibilidade de serem influenciadas por condições favoráveis à germinação nas espigas.

A análise geral dos resultados deixou claro que a cultivar 'Frontana' apresentou valores insignificantes de germinação na espiga. A expressão da dormência, citada por FLINTHAM (2000), parece ter sido o mecanismo mais evidente, pois as menores notas de germinação estiveram associados ao maior

Tabela 1 - Número médio de grãos, grãos germinados e grãos não germinados por espiga, nas localidades de Cascavel e Palotina, 2005.

\begin{tabular}{|c|c|c|c|c|c|c|c|c|c|c|c|c|c|}
\hline \multirow[b]{3}{*}{1} & \multirow{3}{*}{$\begin{array}{l}\text { Tratamento } \\
\text { BRS } 177\end{array}$} & \multicolumn{4}{|c|}{-------Número médio de Grãos------- } & \multicolumn{4}{|c|}{----------Grãos germinados----------- } & \multicolumn{4}{|c|}{--------Grãos não germinados-------- } \\
\hline & & \multicolumn{2}{|c|}{ Cascavel } & \multicolumn{2}{|c|}{ Palotina } & \multicolumn{2}{|c|}{ Cascavel } & \multicolumn{2}{|c|}{ Palotina } & \multicolumn{2}{|c|}{ Cascavel } & \multicolumn{2}{|c|}{ Palotina } \\
\hline & & 43,5 & $\mathrm{aA} *$ & 30,2 & bB & 30,0 & $\mathrm{dA}$ & 6,5 & bB & 70,0 & $\mathrm{cB}$ & 93,6 & bA \\
\hline 2 & BRS 208 & 41,9 & $\mathrm{aA}$ & 32,8 & $\mathrm{aB}$ & 39,2 & cA & 9,1 & bB & 60,8 & $\mathrm{~dB}$ & 90,9 & $\mathrm{bA}$ \\
\hline 3 & BRS 210 & 47,8 & $\mathrm{aA}$ & 25,8 & bB & 35,7 & $\mathrm{cA}$ & 12,8 & bB & 64,3 & $\mathrm{~dB}$ & 87,2 & bA \\
\hline 4 & CD 104 & 44,9 & $\mathrm{aA}$ & 35,2 & $\mathrm{aB}$ & 36,7 & $\mathrm{cA}$ & 6,5 & bB & 63,4 & $\mathrm{~dB}$ & 93,5 & bA \\
\hline 5 & CD 105 & 43,3 & $\mathrm{aA}$ & 30,5 & bB & 39,0 & cA & 6,7 & bB & 61,0 & $\mathrm{~dB}$ & 93,3 & bA \\
\hline 6 & CD 108 & 38,4 & $\mathrm{aA}$ & 26,3 & bB & 18,5 & eA & 1,8 & $\mathrm{cB}$ & 81,5 & bB & 98,2 & aA \\
\hline 7 & Frontana & 39,3 & $\mathrm{aA}$ & 36,9 & $\mathrm{aA}$ & 0,3 & fA & 0,3 & $\mathrm{cA}$ & 99,7 & $\mathrm{aA}$ & 99,7 & $\mathrm{aA}$ \\
\hline 8 & IAPAR 53 & 36,9 & $\mathrm{aA}$ & 27,7 & bB & 4,9 & fA & 1,2 & $\mathrm{cA}$ & 95,1 & $\mathrm{aA}$ & 98,8 & $\mathrm{aA}$ \\
\hline 9 & IPR 85 & 40,7 & $\mathrm{aA}$ & 29,0 & bB & 34,1 & $\mathrm{dA}$ & 4,7 & $\mathrm{cB}$ & 65,9 & $\mathrm{cB}$ & 95,4 & $\mathrm{aA}$ \\
\hline 10 & OCEPAR18 & 37,8 & $\mathrm{aA}$ & 29,7 & bB & 60,2 & $\mathrm{aA}$ & 24,8 & $\mathrm{aB}$ & 39,8 & $\mathrm{fB}$ & 75,2 & cA \\
\hline 11 & ONIX & 43,2 & $\mathrm{aA}$ & 30,0 & bB & 5,8 & fA & 1,8 & cA & 94,2 & $\mathrm{aA}$ & 98,2 & $\mathrm{aA}$ \\
\hline \multirow[t]{2}{*}{12} & Trigo BR18 & 39,2 & $\mathrm{aA}$ & 24,7 & bB & 47,8 & bA & 22,8 & $\mathrm{aB}$ & 52,2 & $\mathrm{eB}$ & 77,2 & cA \\
\hline & CV (\%) & 14,4 & & 10,9 & & 17,9 & & 16,5 & & 7,43 & & 3,3 & \\
\hline
\end{tabular}

* Notas ou médias não seguidas de mesma letra, minúscula na coluna e maiúscula na linha, diferem pelo teste de Scott e Knott a 5\% de probabilidade de erro.

Ciência Rural, v.39, n.9, dez, 2009. 
número de sementes dormentes detectado pelo teste de tetrazólio. O estudo comparativo entre as diferentes cultivares destacou 'Frontana' como uma cultivar realmente diferenciada, permitindo separá-la das demais pela consistência de baixos valores, correspondendo a apenas $0,3 \%$ de grãos germinados (Tabela 1 ), e pelas notas igualmente baixas em Cascavel e Palotina, respectivamente 1,1 e 1,0 (Tabela 2 ), as quais correspondem aos valores mínimos da escala.

A capacidade de manutenção da dormência, mesmo sob condições ótimas à germinação na espiga, sugere que esse mecanismo possa representar o fator mais importante a ser utilizado no melhoramento da tolerância à germinação. Transferida para novas cultivares, a dormência poderá propiciar um novo marco para a cultura do trigo em regiões sujeitas à germinação antes da colheita, resultando em produtos com maior potencial de comercialização, dando atendimento às necessidades da indústria. A obtenção de qualidade dentro de um padrão exigido pelo mercado, em quantidades próximas ao ideal, poderá garantir estabilidade nas regiões produtoras e favorecer a busca da autossuficiência. Assim, cabe à pesquisa disponibilizar cultivares mais produtivas e capazes de manter as características essenciais requeridas para os diferentes produtos derivados de trigo.

A análise das correlações entre as características de germinação de grãos e notas de germinação revelou valores que apontam para uma estreita associação entre os parâmetros. Tal informação é importante para a escolha de uma metodologia mais simples e rápida para a avaliação da tolerância à germinação na pré-colheita (Tabela 3).
As notas de germinação (NT) conferidas às cultivares nas duas localidades permitiram observar uma clara separação dos materiais com maior nível de tolerância. O mesmo resultado também foi observado por meio de notas visuais de germinação (NTV), sugerindo que a avaliação visual seja válida, na medida em que não compromete a seleção dos genótipos mais tolerantes.

A determinação da nota de germinação na primeira inspeção visual dos grãos, logo após encerrar o período de molhamento, permitiu fazer avalições rápidas em um grande número de cultivares. A alta correlação entre os resultados indicou a utilidade desse critério de avaliação sob condições satisfatórias para a germinação, pois as cultivares suscetíveis registraram valores consistentes, de médios a altos. Por outro lado, embora as notas possam ser menos discriminatórias em determinados casos, torna-se mais difícil discernir entre as cultivares de maior tolerância e as de tolerância parcial. É provável que, mesmo nessa situação, o emprego das notas ainda poderia ser de utilidade prática, pois indicaria, pelo menos, as cultivares de maior suscetibilidade.

A percentagem de grãos germinados (GG) esteve perfeitamente ajustada aos valores de NT, pois o menor número de grãos germinados correspondeu às menores notas de germinação (Tabela 3). Também foi detectada uma alta correlação, mas negativa, entre a NTV e a percentagem de grãos não germinados (NG). Os valores observados favoreceram a identificação dos extremos, gerados pelas cultivares com melhor tolerância em relação aos sucetíveis. As cultivares que

Tabela 2 - Médias de notas e de notas visuais de germinação nas espigas, nas localidades de Cascavel e Palotina, 2005.

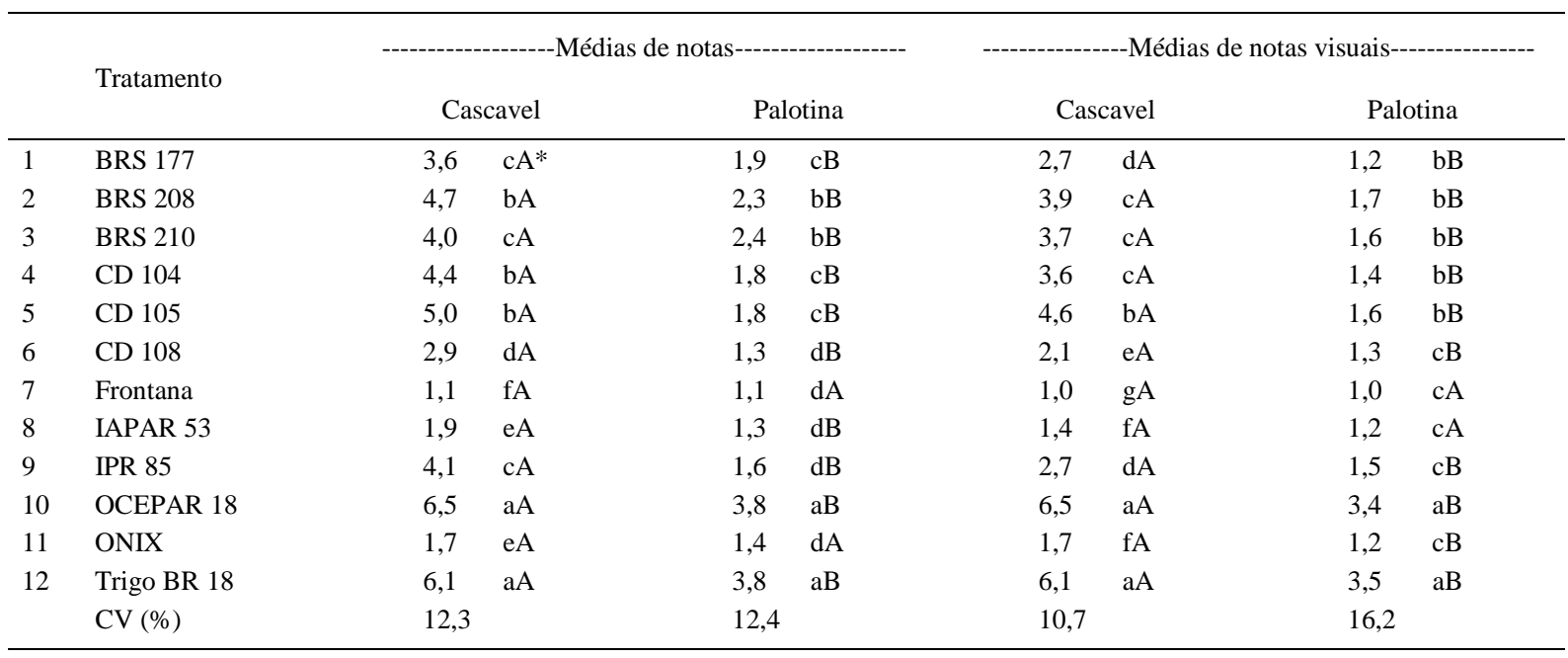

* Notas ou médias não seguidas de mesma letra, minúscula na coluna e maiúscula na linha, diferem pelo teste de Scott e Knott a 5\% de probabilidade de erro. 
Tabela 3 - Correlação entre as características grãos germinados (GG), grãos não germinados (NG), nota (NT) e nota visual (NTV), em Palotina e Cascavel, 2005.

\begin{tabular}{|c|c|c|c|c|c|c|c|c|}
\hline Característica & $\begin{array}{c}\text { GG } \\
\text { Palotina }\end{array}$ & $\begin{array}{c}\text { NG } \\
\text { Palotina }\end{array}$ & $\begin{array}{c}\text { NT } \\
\text { Palotina }\end{array}$ & $\begin{array}{c}\text { NTV } \\
\text { Palotina }\end{array}$ & $\begin{array}{c}\text { GG } \\
\text { Cascavel }\end{array}$ & $\begin{array}{c}\text { NG } \\
\text { Cascavel }\end{array}$ & $\begin{array}{c}\text { NT } \\
\text { Cascavel }\end{array}$ & $\begin{array}{c}\text { NTV } \\
\text { Cascavel }\end{array}$ \\
\hline GG - Palotina & 1 & & & & & & & \\
\hline NG - Palotina & -1 & 1 & & & & & & \\
\hline NT- Palotina & 0.99 & $-0,99$ & 1 & & & & & \\
\hline NTV - Palotina & 0.96 & $-0,96$ & 0.96 & 1 & & & & \\
\hline GG - Cascavel & 0.85 & $-0,85$ & 0.85 & 0.77 & 1 & & & \\
\hline NG - Cascavel & $-0,85$ & 0.85 & $-0,85$ & $-0,77$ & -1 & 1 & & \\
\hline NT - Cascavel & 0.87 & $-0,87$ & 0.87 & 0.82 & 0.99 & $-0,99$ & 1 & \\
\hline NTV - Cascavel & 0.93 & $-0,93$ & 0.93 & 0.90 & 0.94 & $-0,94$ & 0.97 & 1 \\
\hline
\end{tabular}

formaram o grupo intermediário puderam ser facilmente identificadas por estarem mais próximas ao grupo tolerante ou por estarem próximas ao grupo gerado por cultivares com maior suscetibilidade.

O método da contagem de grãos germinados é muito mais demorado e trabalhoso do que o método de atribuição de notas de germinação, especialmente quando se trata de avaliar um grande número de cultivares. Os resultados apontaram claramente para uma grande coincidência avaliativa das duas metodologias, indicando que as notas podem substituir perfeitamente as avaliações demoradas de contagem de grãos germinados por espiga. É natural, portanto, que seja discutida a forma de obtenção das notas.

A coincidência entre as notas visuais de germinação e as notas determinadas pela acurada verificação da emissão de radículas e coleóptilos indicou que qualquer uma das formas de se atribuir uma nota às cultivares foi capaz de separar eficientemente as diferentes classes de tolerância. Em outras palavras, a correlação tornou evidente que as duas metodologias caracterizaram as mesmas cultivares com níveis similares de tolerância. Entretanto, a atribuição de notas visuais é mais rápida que o emprego meticuloso de notas fundamentadas na contagem e mensuração de estruturas germinativas. Nesse caso, os resultados recomendam o uso expedito de notas visuais em um programa de melhoramento, por ser um procedimento mais apropriado à pronta seleção de cultivares com maior tolerância à germinação na espiga. Para tanto, porém, é necessário que o tempo de molhamento através de chuva artificial seja suficientemente longo, a fim de propiciar uma clara separação de grupos divergentes na manifestação do caráter.

As condições de ambiente, onde são cultivados trigos no Brasil, favorecem a ocorrência de chuvas no momento da colheita (CUNHA et al., 2004; BASSOI, 2004), podendo causar, para a maior parte das cultivares, uma acentuada perda de potencial de germinação e de qualidade industrial. Entretanto, os resultados dos diferentes testes utilizados para identificar as cultivares com melhor tolerância à germinação na espiga indicam que existe possibilidade de manter os grãos com as propriedades adequadas para a indústria. Essa identificação das cultivares com menor número de grãos germinados representa uma possibilidade de mudar a quantidade de perdas ocorrentes nas regiões produtoras de trigo. A importância desse fator está diretamente relacionado aos problemas de comercialização, principalmente, nos Estados do Paraná e Rio Grande do Sul, que são os Estados exportadores de trigo ou farinha para outras regiões do país.

Melhoramentos para a incorporação desse caráter de tolerância à germinação na pré-colheita em novas cultivares serão necessários, pois poucas cultivares apresentaram baixa germinação. Os resultados obtidos indicam que o melhoramento deve voltar à origem da base genética do 'Frontana' para incrementar o nível de tolerância à germinação na espiga e garantir maior segurança na produção de trigos com padrão adequado para a industrialização. Esse procedimento propiciará alcançar a segurança e estabelecer um padrão de trigos mais adequados com as condições de ambiente das regiões produtoras.

\section{CONCLUSÕES}

As espigas das cultivares de trigo submetidas a um sistema de chuva artificial permitiram gerar resultados baseados na contagem de grãos germinados e não germinados, que possibilitaram identificar as cultivares 'Frontana', 'IAPAR 53', 'ÔNIX', 'CD 108' e 'IPR 85' como as de melhor nível de tolerância. Entre essas, a cultivar Frontana apresentou o melhor mecanismo de tolerância à germinação na espiga, quando foram consideradas todas a características avaliadas.

Ciência Rural, v.39, n.9, dez, 2009. 
A utilização da metodologia de notas visuais de germinação na espiga, para caracterizar as diferenças de tolerância, permitiu avaliar com rapidez um grande número de cultivares, sem comprometer os resultados da seleção dos genótipos mais tolerantes determinados pela contagem de grãos germinados.

\section{REFERÊNCIAS}

BASSOI, M.C. Introdução ao problema da germinação précolheita em trigo no Brasil. In: CUNHA, G.R.; PIRES, J.L.F. (Ed.). Germinação pré-colheita em trigo. Passo Fundo: Embrapa, 2004. p.21-136.

BASSOI, M.C.; FLINTHAM, J. Relationship between grain colour and prehervest sprouting-resistance in wheat. Pesquisa Agropecuária Brasileira, v.40, n.10, p.981-988, 2005. Disponível em: <http://webnotes.sct.embrapa.br/pab/pab.nsf/ FrAutor>. Acesso em 9 jul 2009.

BASSOI, M.C. et al. Analysis of preharvest sprouting in three Brazilian wheat populations. Pesquisa Agropecuária Brasileira, v.41, n.4, p.583-590, 2006. Disponível em: <http:/ /webnotes.sct.embrapa.br/pab/pab.nsf/FrAutor>. Acesso em 9 jul 2009.

BELDEROCK, B. Changes in the seed coat of wheat kernels during dormancy and after-ripening. Cereal Research Communications, v.4, p.165-171, 1976.

BRASIL. Ministério da Agricultura e Reforma Agrária. Manual do teste de tetrazólio em sementes. Brasília, DF: AGIPLAN, 1976. 85p.

CASTRO, R.D. et al. Embebição e reativação do metabolismo. In: FERREIRA, A.G.; BORGHETTI, F. (Orgs.). Germinação do básico ao aplicado. Porto Alegre: Artmed, 2004. p.149162.

CRUZ, C.M. Programa genes. Aplicativo computacional em genética e estatística. Viçosa: UFV, 2001. 422 p. Disponível em: <http://www.ufv.br/dbg/genes/genes.htm>. Acesso em 9 jul 2009 .

CUNHA, G.R. et al. Introdução ao problema da germinação na pré-colheita em trigo no Brasil. In: CUNHA, G.R.; PIRES, J.L.F. Germinação pré-colheita em trigo. Passo Fundo: Embrapa, 2004. p.11-20.
FLINTHAM, J.E. Different genetic components control coatimposed and embryo-imposed dormancy in wheat. Seed Science Research, v.10, p.43-50, 2000.

FRANCO, F. de A.; CARVALHO, F.I.F. Estimativa do progresso genético no rendimento de grãos de trigo e sua associação com diferentes caracteres sob o efeito de variações de ambiente. Pesquisa Agropecuária Brasileira, v.37, n.3, p.1-9, 1985.

HAGEMANN, M.G.; CIHA, A.J. Evaluation of methods used in testing winter wheat susceptibility to preharvest sprouting. Crop Science, v.24, p.249-254, 1984

HANFT, J.M.; WYCH, R.D. Visual indicators of physiological maturity in hard red spring wheat. Crop Science, v.22, p.584587, 1982

HILHORST, H.W.M. A critical update on seed dormancy. I. Primary dormancy. Seed Science Research, v.5, p.1-73, 1995.

INSTITUTO AGRONÔMICO DO PARANÁ. Informações técnicas para as culturas do trigo e triticale no Paraná 2003. Londrina: IAPAR, 2003. 202p. (Circular, 126).

KATO, K. et al. Detection of loci controlling seed dormancy on group 4 chromosomes of wheat and comparative mapping with rice and barley genomes. Theoretical and Applied Genetics, v.102, p.980-985, 2001.

LUNN, G.D. et al. Mechanisms leading to excess alpha-amylase activity in wheat (Triticum aestivum, L.) grain in the U.K. Journal of Cereal Science, v.33, p.313-329, 2001.

McMASTER, G.J.; DERERA, N.F. Methodology and sample preparation when screening for sprouting damage in cereals Cereal Research Communications, v.4, n.2, p.251-254, 1976.

OKUYAMA, L.A. et al. Avaliação de cultivares de trigo quanto à germinação na espiga. In: REUNIÃO DA COMISSÃO CENTRO SUL BRASILEIRA DE PESQUISA DE TRIGO, 18, 2003, Guarapuava, PR. Palestras, Resumos e Atas... Guarapuava: Fundação Agrária de Pesquisa Agropecuária, 2003. p.191-193.

REDDY, L.V. et al. Effect of temperature on seed dormancy of wheat. Crop Science, v.25, p.455-458, 1985.

REIS, M.S.; CARVALHO, F.I.F. Eficiência de três métodos artificiais para identificação da variabilidade do caráter germinação na espiga em trigo. Revista Brasileira de Fisiologia Vegetal, v.1, n.1, p.63-72, 1989. 